Palimpsesto Vol. 10, № 17 (enero-junio, 2020): 247-266

Universidad de Santiago de Chile, ISSN 0718-5898

Francisca Rengifo Streeter

Universidad Adolfo Ibáñez

francisca.rengifo@uai.cl

\title{
Poder municipal. La territorialización del gobierno estatal en Chile, 1830-1890*
}

\author{
Municipal Power. The Territorialization Process of the Chilean \\ Central Government, 1830-1890
}

\begin{abstract}
Resumen
Este artículo ofrece un estudio empírico del proceso de anclaje territorial del Estado chileno durante el siglo XIX, atendiendo a las formas de articulación entre el gobierno central y las municipalidades. La pregunta que guía el análisis es cómo el poder estatal ha sido localmente construido. Para responder, argumenta que el municipio fue un espacio político que articuló a nivel local el ejercicio de dicho poder, institucionalizando a la vez que asentando una concepción moderna del mismo. Desde esta perspectiva, la municipalidad como anclaje territorial del Estado, el proceso de construcción estatal es redimensionado localmente a partir del análisis de otra forma de poder distinguible del aparato central. Sus resultados recuperan el protagonismo de las municipalidades como otros centros de poder que dinamizan los procesos de institucionalización y concreción territorial del gobierno, y discuten la interpretación estadocéntrica del Estado chileno que ha reproducido el mito de una histórica debilidad municipal.
\end{abstract}

Palabras claves: municipalidad, poder local, gobierno interior, construcción de Estado.

\begin{abstract}
This article offers an empirical study of the process of territorial anchoring of the Chilean State during the 19th century, taking into account the forms of articulation between the central government and the municipalities. The main question is how state power has been locally built. The answer argues that the municipality was a political space that articulated at the local level the exercise of this power, institutionalizing at the same time as establishing a modern conception of it. From this perspective, the process of state construction is resized locally by the analysis of another form of power distinguishable from the central apparatus. In doing so, it allows to recover the protagonism of the municipalities as other centers of power that dynamize the processes of institutionalization and territorial concretion of the

* Artículo de investigación, en el marco del proyecto "Democracia en Chile" del Centro de Estudios de Historia Política de la Universidad Adolfo Ibáñez. Agradezco especialmente a Andrés Estefane por la aguda discusión sobre conceptos y nociones centrales a este artículo, así como rigurosa lectura.
\end{abstract}


government and discuss the monocentric interpretation of the Chilean State that has reproduced the myth of a historical municipal weakness.

Keywords: municipalities, local power, central government, State-Building.

\section{Introducción}

La formación de los estados latinoamericanos estuvo impregnada por las tensiones y los conflictos entre los promotores de ordenamientos institucionales altamente centralizados y aquellos que propugnaban esquemas proclives a la dispersión territorial del poder. Este debate, que llevó a enfrentamientos armados y guerras civiles en varios casos, fue primero ideológico antes que político. Inicialmente, las instituciones de poder local fueron consideradas como la condición necesaria para garantizar la libertad y la igualdad respecto del gobierno arbitrario que representaba el de Antiguo Régimen. Paulatinamente, las intendencias, los cabildos y ayuntamientos fueron reemplazados por nuevas entidades de gobierno local en un proceso que se apoyó de modo pragmático en los primeros. Este cambio no ocurrió sobre un vacío institucionaladministrativo, sino que hubo continuidades respecto del ordenamiento borbónico junto a las novedades políticas que significaba la organización de las nacientes repúblicas. La novedad y desafío mayor era concretar la soberanía de la nación, reconociendo en lo territorial una de las fuentes cruciales para la construcción de la legitimidad demandada por los actores y las instituciones que localizaron e hicieron posible el ejercicio del poder político reclamado por el naciente Estado. En Chile, este proceso de localización estatal puso en marcha prácticas políticas definidas al calor de los debates en torno a cuál era la forma más efectiva de gobierno en función de la escala local y en relación al grado de intervención por parte del gobierno central.

Las actuales agendas de descentralización y desconcentración administrativa expresan la vigencia de este problema político, redefiniendo lo territorial como un elemento indispensable para repensar las formas de gobierno. Las instituciones de gobierno local, que aparte de ser laboratorios en los que se puede conocer en detalle las lógicas que a la fecha han ordenado la distribución del poder político, también emergen como uno de los espacios más apropiados para proyectar nuevas formas de ordenamiento (Rosanvallon, 2015; Loughlin et. al., 2011; Grindle, 2009; O’Neill, 2005; Roberts, 1998; Marcel, 1994). En Chile, los debates que emparentan las demandas de democratización con la territorialización del ejercicio del poder han sido de suma relevancia desde el fin de la dictadura militar de Augusto Pinochet (1973-1990), porque arrancan de la profunda reforma político-administrativa implementada por dicho régimen en la segunda mitad de la década de 1970 (Faúndez, 2011; Drake, 2009; Posner, 2003; Rehren, 2001; Angell et al., 2001; Rosenfeld et al., 1989). Conocida como la "regionalización", dicha reforma transformó de manera radical el ordenamiento histórico del país -cuyas raíces se remontaban al siglo XIXreemplazando a las antiguas provincias por las nuevas regiones, disminuyendo el número de unidades de gobierno y administración y redefiniendo el papel político de las municipalidades, las cuales se convertirían en un espacio clave para el proceso de resocialización de la población bajo los principios de la economía de mercado y los requerimientos de un Estado subsidiario (Estefane, 2017; Salazar, 2014; Valdivia et al., 2012; Angell et al., 2001). El carácter revolucionario de esta reforma discutida durante décadas en el sistema político chileno y que los militares solo pudieron implementar en un contexto de excepcionalidad institucional, radica no 
solo en haber inaugurado una nueva era en la historia de la organización territorial del país, sino también en haber fijado el marco en el cual se han ido desarrollando las discusiones en torno a la reconstrucción de la democracia y el ejercicio del poder tanto a nivel regional como local.

Los debates políticos y las discusiones disciplinarias sintetizan la pregunta por cuál es el lugar dentro del gobierno nacional que ocupan los espacios locales de poder político, cuya respuesta exige un análisis empírico. Si bien las unidades administrativas subnacionales, especialmente las vinculadas al gobierno local, gravitan hoy como espacios de sumo interés para repensar la democracia y la participación ciudadana, dicha rehabilitación no se ha visto acompañada de una renovada reflexión histórica respecto a sus trayectorias. Por un lado, el diagnóstico político contemporáneo expresa un optimismo que sobredimensiona el potencial democratizador de las instituciones de gobierno local (proyectando al presente los componentes de autonomización y anticentralismo que animaron experiencias pretéritas) y, por otro, esta expectativa contrasta con un pesimismo paralizante que desestima esa capacidad, afirmando que en la trayectoria estatal chilena las municipalidades no han sido más que agencias o prolongaciones del gobierno central. Ambas perspectivas desconocen que la primera tradición historiográfica chilena, y también en latinoamericana, fue la institucional-constitucionalista imbuida de una narrativa progresista que contribuye poco a comprender los procesos de formación estatal, no porque sus conclusiones sean erradas, sino debido a que carecen de potencial explicativo (Adelman, 1998).

El propósito de este artículo es contribuir a la discusión de dichos apresurados supuestos desde la perspectiva histórica. Chile supone un Estado histórica y altamente centralizado, ensombreciendo la posición que ocupan las instituciones locales de poder. Tanto durante gobiernos democráticos como bajo regímenes autoritarios y dictadura, el grado de autonomía municipal ha sido estimado como reducido. La escasez de estudios sobre las municipalidades, campo en el cual ha predominado la aproximación jurídico-constitucionalista, ha contribuido a la reproducción de un doble diagnóstico de debilidad institucional y política determinada por la dependencia administrativa del municipio al gobierno central, la consiguiente crónica falta de recursos económicas y una persistente intervención en dicho cuerpo por parte de los partidos políticos. Asimismo, tal supuesto carácter marginal del municipio ha significado una ausencia o figuración secundaria de la municipalidad como un actor relevante dentro de la historiografía política. Esta mirada opaca ha sido reforzada por el predominio de la noción de un Estado unitario fuertemente centralizado, soslayando el rol clave que las municipalidades tuvieron como engranajes territoriales de sus agentes y organismos (Donoso, 1946; Heisse, 1950 y 1974; Gil, 1969; Véliz, 1980; Faúndez, 2011).

Desde los inicios de la república, el principio político del municipio como gobierno local fue engranándose sobre la base de los escasos centros de población existentes y subordinado a la autoridad central (Valdebenito, 1973; Cleaves, 1969 y 1974). No obstante, esta constatación ha sido expresada en los términos estatales de centralización del poder. Por un lado, el debate ideológico de las primeras décadas de formación republicana sintetizó al cabildo como una proyección colonial que pesaba como una herencia inerte, impidiendo convertir a los municipios en una institución republicana de gobierno local entendido como autogobierno (Tocqueville, 1835-40; Briseño, 1849; Peña, 1855; Carrasco, 1858). En consecuencia, el municipio habría permanecido como un espacio adormecido sin transformaciones hasta mediados del siglo XIX, cuando los primeros esfuerzos de control y reorganización expresados en la primera ley orgánica de municipalidades de 1854 quiso imponer un orden burocrático inserto en el proceso de formalización administrativa del poder Ejecutivo, el cual sería posteriormente reforzado con la 
siguiente ley orgánica de 1887 (Concha, 1905; Letelier, 1907; Roldán, 1913; Correa, 1914; Alemparte, 1940). Por otro, las reformas de fines de siglo apelaron al ideario liberal de gobierno subrayando el rol fundamental del municipio como forma de autogobierno local; sin embargo, estas tuvieron un carácter centralizador restando considerable autonomía a las municipalidades.

Ambas leyes constituyen hitos político-institucionales que delimitan un periodo emblemático por los procesos de distribución del poder en unidades administrativas enmarcados en el problema del gobierno territorial por parte del Estado. En las primeras décadas del siglo, el ideario federal instaló al municipio al centro de su proyecto político de organización nacional mirando a los Estados Unidos de Norteamérica- y en oposición al centralismo estatal promovido por la facción política conservadora (Collier, 2003 y 2012; Illanes, 2003; Villalobos, 1986; Scully, 1992). A mediados de la centuria, los municipios tuvieron un protagonismo como plataformas políticas para el estallido revolucionario de 1851 que también podría considerarse como un factor para querer intervenirlas desde el gobierno central (Fernández, 2007). Nuevamente, en el último tercio del siglo XIX, la municipalidad ocupó un lugar central en los debates por las reformas constitucionales y del régimen electoral que permitirían concretar la asimilación de una más amplia representación política en el establecimiento de las primeras instituciones autónomas.

Resulta necesario, por tanto, insistir en la especificidad de la pregunta por el gobierno del territorio para explicar bajo qué términos se ha entendido el anclaje espacial del Estado y también cómo esa comprensión definió la trayectoria a favor de un ordenamiento jerárquicamente centralizado como una de las características que, a pesar de las mutaciones ideológicas del período, define al sistema político chileno a lo largo del siglo XIX. Con el fin de proveer una necesaria densidad histórica sobre la cual poder además discutir la interpretación mono-céntrica del proceso de formación estatal chilena, este artículo analiza empíricamente el anclaje territorial en el periodo descrito, atendiendo a las formas de articulación entre el gobierno central y las municipalidades. La pregunta que guía el análisis es cómo el poder estatal ha sido localmente construido. ¿Cuáles han sido los modos específicos, los mecanismos, las tensiones a través de las cuales ocurre la distribución territorial del poder? ¿Cuáles opciones políticas y cómo los procesos que emergen de sus implementaciones institucionalizan y concretizan al municipio como elemento constitutivo de gobierno local dentro del régimen político chileno? La respuesta implica examinar la cuestión del poder municipal atendiendo a la doble dimensión de su origen y su ejercicio. La primera supone la libre elección de los miembros que componen el gobierno local por quienes este representa $\mathrm{y}$, la segunda, supone la delimitación de un espacio de acción autónoma del central estatal definido por las atribuciones, funciones, recursos jurisdiccionales, políticos y económicos involucrados. Ambos aspectos no necesariamente han ido entrelazados y para comprehender adecuadamente a la municipalidad como bisagra constitutiva del Estado chileno es pertinente distinguirlos (Loughlin 1996). ${ }^{1}$

El estudio del problema territorial en relación a la distribución del poder a nivel local en las municipalidades tiene un estrecho vínculo con el de la representación política, institucionalizada en elecciones periódicas, maquinarias partidarias y rotación de autoridades, entre otros fenómenos (Antonio y Guerra, 2003; Annino y Ternaviaso, 2012; Valenzuela, S. 1985; Valenzuela, A. 1977). Precisamente, a partir de la acumulación de evidencia provista por

\footnotetext{
${ }^{1}$ Martin Loughlin revaloriza la interpretación legal-constitucional de las relaciones central-local subrayando la importancia de la dimensión legal en el estudio de estas, porque examina cada pieza significativa de la legislación sobre gobierno que haya afectado el ámbito de acción del gobierno local.
} 
dicha línea de investigación, el presente análisis se concentra en el aspecto menos estudiado del problema referente al proceso de localización espacial del gobierno estatal. En primer lugar, es pertinente evaluarlo bajo coordenadas que vayan más allá de la oposición fundante entre monocentrismo y descentralización, pues aunque no se pueda prescindir del todo de ella, la complejidad de la administración política y el gobierno de las periferias no siempre se limitaron a las tensiones derivadas de ese binomio. En segundo lugar, parece pertinente un análisis histórico que establezca relaciones de inteligibilidad entre los vínculos del ordenamiento nacional y el gobierno local en vez de causalidad ya que, de este modo, es posible ecualizar los efectos dicotómicos antes descritos, situando el debate en coordenadas institucionales que fortalezcan los esfuerzos contemporáneos por resignificar la relación entre democracia y territorio. Por tanto, el foco de atención está puesto sobre el ejercicio del poder municipal en las unidades territoriales de administración definidas como tal, por ser estas los espacios donde se tradujo concretamente la noción nacional del Estado chileno, así como los márgenes de participación reclamados por (o concedidos a) los actores locales en la regularización de los vínculos de dependencia burocrática.

La literatura especializada ha tendido a registrar este proceso como consecuencia del empuje descentralizador o, a la inversa, como una derrota para el centralismo. Sin embargo, como sostiene este artículo, tal denominado proceso de autonomía se vio en la práctica limitado por un nuevo tipo de subordinación al gobierno central. Para ello, examina los procesos de construcción estatal enfatizando la dimensión territorial del poder político, reconociendo en lo espacial una de las fuentes cruciales para la construcción de la legitimidad del poder, en el marco del desarrollo del ordenamiento y régimen de gobierno interior de la república que tuvo como objetivo establecer una división política-administrativa del territorio nacional que reafirmara la soberanía del Estado. A nivel local, el foco político de este desarrollo fue el municipio, entendido no solo como el escenario donde se ancló el poder y donde se fue asentando una concepción moderna del mismo, sino también donde se pusieron en marcha prácticas políticas definidas al calor de los debates en torno a cuál era la forma más efectiva de gobierno en función de la escala local y en relación al grado de intervención por parte del gobierno central. Esta hipótesis apunta a recuperar el protagonismo de las municipalidades observándolas como otros centros de poder que dinamizan los procesos de institucionalización y concreción territorial del gobierno (Rose y Miller, 1992). ${ }^{2}$ Argumenta que el municipio fue un espacio político-institucional que articuló a nivel local el ejercicio del poder del Estado, redimensionado de esta forma el proceso de construcción estatal localmente a partir del análisis de otra forma de poder distinguible del aparato central (Carmagnani, 2007).

Con el fin de entender qué significa la constitución territorial del gobierno nacional, este artículo está dividido en dos secciones y una tercera conclusiva. Los orígenes del municipio como la menor unidad política- administrativa del Estado han sido convencionalmente identificados con la Constitución Política de 1833 y con su implementación territorial diseñada por la primera ley orgánica de municipalidades de 1854. No obstante, la primera sección da cuenta de sus antecedentes y cómo el problema de lo territorial en el gobierno nacional fue central a los primeros ordenamientos interiores. Durante estas primeras décadas, los procesos de distribución espacial y articulación del poder político configuraron la naturaleza de los vínculos entre el gobierno central y las municipalidades. En la práctica, el municipio significó un espacio más o menos amplio de acción en parte debido a la indefinición normativa que tuvieron inicialmente estas entidades corporativas. En consecuencia, como analiza la segunda sección, si bien la

${ }^{2}$ Concepto de múltiples centros de gobierno desarrollado por Foucault (2006). 
fórmula centralizada consagrada por la Constitución fue implementada localmente a través del régimen municipal establecido en 1854, no cabe asumir el carácter centralista de estas corporaciones. Por ello, el análisis gira hacia una perspectiva de las posibilidades concretas del poder municipal desde la temporalidad y racionalidad que le es propia a una institución política (Shapiro et al., 2006; Carpenter, 2001; Angell et al., 2001). Asumiendo que la relevancia de estas entidades corporativas no fue políticamente estimada, sino hasta las últimas décadas del siglo XIX, en el contexto del debate por las reformas constitucionales y electorales, la última sección aborda cómo, paradójicamente, el gobierno central podía intervenir, o sus agentes podían comentar hasta el más mínimo detalle relativo a la provisión de servicios del gobierno local. Los años entre 1887 y 1897 fueron un periodo crucial como balance del proceso de territorialización del gobierno nacional porque, una vez consolidado relativamente el régimen interior, se adoptaron las reformas para la subordinación de la institucionalidad municipal.

\section{La localización municipal del poder estatal}

El municipio, denominado también cabildo y/o ayuntamiento, fue el lugar de anclaje del poder político nacional durante la primera mitad del siglo XIX. El temprano debate sobre cómo la naciente república debía gobernarse a sí misma fue implícitamente una discusión sobre la articulación territorial del poder nacional, en la cual no fue evidente la centralización administrativa que, en parte, se ha supuesto retrospectivamente a los primeros ensayos constitucionales. Las leyes federalistas dan cuenta también de que este fue un proceso tensionado $\mathrm{y}$ de transformaciones mutuas entre las formas de gobierno nacional, sub-nacional y local (Estefane, 2017; Sanhueza, 2008). Si bien una aproximación a la constitución del gobierno central subraya la regularidad del proceso y la persistente figura de un poder Ejecutivo que protagoniza la organización de la administración del territorio dividiéndolo en provincias y departamentos bajo su directa jefatura, esta fórmula centralista de la división políticoadministrativa insinúa también un espacio primario a nivel local en el cual la concreción del gobierno nacional fue un proceso dinámico.

En las primeras décadas de construcción republicana la forma de gobierno interior era un proyecto, un horizonte antes que una realidad, en el cual la municipalidad fue parte del proceso de construcción territorial del Estado, a pesar de la jerarquizada grilla espacial que este implicó. Analíticamente, aproximarse a la localización del gobierno evita la distorsión que es suponer al Estado como referido siempre a un centro que ejerce en exclusiva el poder político sobre los individuos que habitan un territorio dado (Lemperiere, 2014). ${ }^{3}$ La cuestión de cómo organizar el gobierno de la república no se respondió sobre un vacío institucional, sino que los esfuerzos y los proyectos constitucionales de las primeras dos décadas de vida independiente se apoyaron en algunas instituciones político-administrativas coloniales con las cuales se quería romper, pero que también ofrecían cierta fortaleza y flexibilidad para acoger una nueva forma de gobierno nacional.

Durante las revoluciones hispánicas, se ideó y debatió el nuevo proyecto republicano en términos de soberanía popular, régimen representativo, constitución de los poderes públicos y garantías individuales, y tanto las alternativas consideradas como las opciones que prevalecieron

${ }^{3}$ Un estudio preciso sobre el concepto de Estado en Iberoamérica en Diccionario político y social del mundo iberoamericano. Conceptos políticos fundamentales, 1770-1870, dirigido por Javier Fernández Sebastián. 
en la constitución y organización estatal fueron respuesta a la pregunta central sobre cuál debía ser la forma de gobierno republicana. El cabildo fue la lógica representativa inicial y la institución negociadora durante la crisis de la independencia política que significó la revolución de la independencia (Lemperiere, 2014; Rojas, 2010; Annino, 1995). ${ }^{4}$ Estos primeros años, entre 1810 y 1830, no debería ser un periodo exclusivamente caracterizado por las luchas independentistas e inestabilidad política, pues queda reducido a un hiato entre el derrumbe imperial y la constitución de la nueva república establecida en 1833. Este tratamiento del periodo identifica a estas décadas como un vacío institucional, a pesar de que es evidente el funcionamiento de entidades y procedimientos de gobierno como demuestran algunos estudios (Serrano, 2008).

Por el contrario, en el cabildo se reconoció su carácter representativo del pueblo y, por tanto, la fuente necesaria de legitimidad del poder (Guerra, 1992), a pesar de que el criterio de vecindad que definía su composición era radicalmente distinto a la idea de comunidad política moderna. ${ }^{5}$ Esta función política inicial definió al municipio como el primer engranaje del sistema político en un periodo de desorden, de contiendas y conflictos armados, representando también un espacio corporativo de cohesión civil. De este modo, el municipio tuvo en estos primeros años de vida independiente un "peso" político antes que administrativo. En los primeros reglamentos constitucionales de 1811, 1812 y 1814, los espacios locales de poder fueron identificados con el ámbito municipal del cabildo y la denominación de provisorios que ellos se dieron es indicador de su carácter circunstancial y abierto a proyectos constitucionales definitivos. Estos reglamentos esbozaron los principios de soberanía popular, régimen representativo, división de los poderes públicos y garantías individuales, refiriéndose a los cabildos como los cuerpos electivos (Anguita, 1912). ${ }^{6}$ Estos eran también una institución urbana existente en los escasos centros que aglomeraban cierta cantidad de población en las tres provincias del país. Más allá de que la década de 1810 estuviera cruzada por la incertidumbre política, y que ello tornara provisional cualquier diseño institucional o administrativo, la emergencia de un ordenamiento territorial tripartito -con Coquimbo, Santiago y Concepción como sus núcleos- fue central para la naturalización de la idea de que la reingeniería del territorio era un componente inseparable de la soberanía (Estefane, 2017).

Tanto la Constitución de 1818 como la de 1822, sin mencionar a la Constitución de 1823 debido a que prácticamente no existió, establecieron al cabildo como un cuerpo electivo y subalterno al poder ejecutivo. ${ }^{7}$ En la práctica, durante esta década no operó el principio de elección directa sino hasta el año 1826, cuando por primera vez se realizaron estas elecciones incluyendo las de intendentes y gobernadores- a lo largo de todo el país en el marco de las leyes federales. Este hecho demuestra no solo la reconocida importancia de la comuna o municipio

\footnotetext{
${ }^{4}$ De acuerdo con Antonio Annino, la articulación entre espacios tradicionales y modernos fue un intento de controlar los cabildos a partir de los municipios.

${ }^{5}$ Por un lado, apelando a las prerrogativas y libertades tradicionales contenidas en la concepción hispano-castellana del municipio -que había sido objeto de control por parte del centralismo absolutista de la metrópolis- con el fin de proponerlo como puntal para apoyar el principio de retroversión del poder y, por otro, a la constitución gaditana de 1812 que convocó a los pueblos a formar cuerpos municipales que eligieran sus representantes ante las Cortes de Cádiz. Andrés Bello subrayó este carácter representativo del pueblo que poseía el cabildo y su papel como defensor de los intereses de las comunidades.

${ }^{6}$ Reglamento para el arreglo de la autoridad ejecutivo provisoria sancionado el 14 de agosto de 1811; Reglamento Constitucional Provisorio de 1812; Reglamento para el gobierno provisorio de 17 de marzo de 1814.

${ }^{7}$ Los cabildos fueron convocados en 1810 para elegir a los representantes al primer Congreso Nacional; en 1811 estos fueron nombrados por la autoridad ejecutiva y, reestablecida la elección popular en el reglamento de 1812, esta no se realizó y cuando en 1819 correspondía renovar a los cabildos, la votación fue suspendida.
} 
como pieza central del ideario federal y de su proyecto político de organización nacional. También constata que las municipalidades sí se habían constituido, aunque solo fuera en circunstancias electorales (Alemparte, 1940). El principio de elección directa de los miembros de la municipalidad fue conservado por la Constitución de 1828, también de muy corta vida, y establecido, finalmente, por la perdurable Constitución de 1833. Un cambio radical, aunque aparentemente nominal, fue que la facultad de crear una municipalidad no fue más entendido un derecho de los pueblos, sino una facultad del Estado. El breve lapso representado por las asambleas provinciales, las cuales debían establecerlas, fue concluido por esta Constitución que entregó esta función al presidente de la República, oyendo al Consejo de Estado.

Si bien el proyecto de organización federal ensayado en 1826 fracasó y tras ello el péndulo se movió hacia un ordenamiento unitario y mono-céntrico, los debates del período 18231826 lograron instalar algunas premisas básicas en el discurso político contemporáneo. Así lo demostró la Constitución liberal de 1828, que coronó los ensayos de la década ecualizando las tesis de un federalismo en retirada y las demandas de quienes empujaban la reinstalación del esquema centralista (Campos Harriet, 1963). En efecto, a nivel subnacional, el gobierno y la administración de las provincias recayó en la Asambleas Provinciales y la figura del intendente, quien era designado por el poder Ejecutivo de una terna elaborada por la asamblea de cada provincia. Nominalmente, las asambleas poseían decisivas atribuciones de supervisión sobre los municipios, las cuales si bien apenas llegaron a concretarse anunciaban formalmente una intención centralizadora. Fue en torno a estas asambleas que se articuló el discurso territorial hegemónico de la década $\mathrm{y}$, en un breve lapso de tiempo, ellas representaron un espacio importante de negociación y defensa de los intereses locales frente a los de la capital, operando como eslabón ineludible en las discusiones en materia de territorio y gobierno interior (Salazar y Pinto, 1999; Galdames, 1925). Sin embargo, tuvieron un estatuto ideológico antes que políticamente efectivo.

Los primeros ordenamientos constitucionales fueron precedidos de un discurso rupturista con el papel del cabildo durante la colonia, pero expresaron explícitamente o por omisión ciertas continuidades institucionales respecto al ejercicio del poder local como gobierno interior de los pueblos. En estas primeras décadas en que la cuestión del gobierno está siendo elaborada en su dimensión nacional, las municipalidades conservaron sus funciones tradicionalmente urbanas de adelantamiento de la población, la industria y la educación, administración de los hospicios, hospitales, aseo y de policía. Sin embargo, en la lógica del proceso administrativo nacional, las intenciones de los dirigentes y elites políticas durante este periodo en materia de organización interior revelan la voluntad de crear un cuerpo de funcionarios propios y autónomo respecto del gobierno central. Estos intereses y las demandas municipales por aumentar sus recursos tensionaron las relaciones entre las autoridades centrales y las locales como manifiestan las memorias del ministerio del Interior. Desde el texto constitucional de 1814 los representantes directos del Ejecutivo presidían los municipios y el canal de comunicación con el gobierno debía ser la Intendencia de la provincia a que correspondían, como especificó nuevamente la Constitución de $1828^{8}$. Esto pone de manifiesto los esfuerzos reiterados por hacer calzar la incipiente institucionalidad estatal con las prácticas políticas del periodo. Los municipios tenían el protagonismo electoral, reuniéndose para nombrar a las juntas calificadoras y receptoras de los sufragios. Por su parte, los agentes del gobierno central reclamaron que los alcaldes y regidores

${ }^{8}$ Fondo Ministerio del Interior (en adelante FMI), vol.76, Comunicaciones con las autoridades de la capital, 1826-30, f. 96. 
sólo estaban interesados en las elecciones, abandonando sus otras funciones de progreso local. Tal actividad y celo, acusó el intendente provincial de Coquimbo, sólo se manifiesta también por el interés de enriquecerse personalmente y abandonar luego el departamento despojándolo de sus recursos. La acusación afectaba al departamento de Ovalle -uno de los más abundantes en recursos minerales y agrícolas de la zona norte del territorio nacional antes de la región desérticaen el cual, subrayó el intendente, las autoridades municipales no atienden ni siquiera los servicios de policía ${ }^{9}$. Estas tensiones repetidas en tiempos eleccionarios y de similares características en otros departamentos del país, ejemplifican los conflictos de poder entre los niveles nacional y local de gobierno. Desde abajo, por ejemplo, la municipalidad de Freirina demandó al gobernador respectivo por mal comportamiento ${ }^{10}$. Los numerosos casos y que fueron canalizados formalmente evidencia que el municipio era un espacio de poder disputado, cuyos miembros defendieron invocando la "costumbre inmemorial" y la ley vigente para reclamar el derecho del alcalde y regidores en orden de precedencia de subrogar al gobernador si este se ausentase del departamento por enfermedad, muerte $u$ otro legítimo impedimento ${ }^{11}$.

Las comunicaciones oficiales de los municipios revelan, como contraparte, otro foco de tensiones provocadas por el traslape de funciones entre los respectivos niveles de gobierno ${ }^{12}$. Los agentes del Ejecutivo recurrían a los empleados municipales para procedimientos del gobierno central y, al mismo tiempo, duplicaban las tareas de los municipios ante las aún indefinidas atribuciones del poder político. Los registros sobre el nivel local de este problema, que a nivel nacional fue resolver la cuestión del gobierno del territorio, aparentemente reproducen un espacio de desorden y precariedad malentendido que bien pudo significar otras prácticas administrativas, las cuales no eran parte de la lógica de un Estado organizándose centralizadamente. El examen de las fuentes oficiales -los reglamentos, leyes, decretos, oficios y las comunicaciones- dan pocas luces sobre la acción de las municipalidades. Estas comienzan a regularizar una presencia formal en la medida en que requirieron definir sus recursos propios y de administración separada del gobierno central a través de la elaboración anual del presupuesto. Sin embargo, esta tímida pero creciente figuración desde la perspectiva estatal no significa necesariamente desorden. Este proceso de institucionalización promovió formas de cohesión interna a las administraciones locales que no deberían percibirse sólo como interferencias de la mayor sobre la menor.

Los otros aspectos más desapercibidos del proceso de formación estatal pueden ser en parte desentrañados atendiendo al proceso mismo de configuración del poder municipal. Lo esencial del proyecto político conservador en lo referido al gobierno y la administración del territorio se sintetizó en la Constitución de 1833, el Reglamento Electoral de ese mismo año y en la Ley de Régimen Interior sancionada en 1844. En esta regulación ya se anticipa el concepto de jurisdicción administrativa. La primera novedad republicana fue que el municipio debía componerse por alcaldes y regidores, cuyo número era determinado por la ley y con arreglo a la población del departamento o territorio señalado a cada municipalidad. De este modo, el criterio espacial prevaleció por sobre el antiguo de vecindad y, como resultado, ya en la década del ' 40 se había formado una administración local impulsada desde las propias municipalidades

${ }^{9}$ FMI, vol. 146, 1835-1846, Oficio de la Intendencia de Coquimbo al Ministro del Interior, Serena, febrero 20 de 1843 , f. 173.

${ }^{10}$ FMI, vol.178, Expedientes judiciales 1837-39, Municipalidad de Freirina contra el gobernador don Rafael Varas por no poder soportar más su comportamiento.

${ }^{11}$ Ley de 15 de diciembre de 1826 sobre empleados municipales y MFI, vol.146, f. 226.

${ }^{12}$ Memorias del Ministerio del Interior (en adelante MMI), años 1835, 1836 y 1839 dan cuenta de la precaria situación financiera de los municipios descrita por los informes de los intendentes y gobernadores. 
gestionando sus recursos. Lo que para algunos intendentes era displicencia por parte de los miembros del municipio, alegando "incorrecciones" en los presupuestos; para varias municipalidades eran "vacíos" debido a la escasez de los recursos locales. ${ }^{13}$

Tanto la Constitución como la ley de Régimen Interior establecieron y regularon a estas entidades corporativas como instituciones insertas subordinadamente al gobierno nacional ${ }^{14}$. $\mathrm{Si}$ bien la ley de 1844 organizó el gobierno interior señalando las atribuciones de todos los encargados de la administración provincial y el modo de ejercer sus funciones, reguló muy superficialmente a las municipalidades. Ellas existían en todas las ciudades y villas cabeceras departamentales con una vida azarosa, a la vez que relevante, a juzgar por los esfuerzos de control y reorganización política durante el gobierno de Manuel Montt y la voluntad de intervenirlas por el protagonismo que tuvieron como plataformas de organización política en el estallido revolucionario de $1851^{15}$. Esto evidencia que eran un espacio de poder, en parte temido, y también da cuenta de las tensiones entre los municipios y el gobierno central provocados por la interpretación práctica del alcance de sus respectivos poderes ${ }^{16}$. El Ejecutivo quiso reforzar su control sobre los municipios, implementando sus atribuciones de poder estipuladas en la Constitución y en el régimen interior a través de los intendentes provinciales y los gobernadores departamentales, quienes debían operar como supervisores directos del funcionamiento de estas corporaciones. Las tensiones sobre el poder municipal fue una cuestión sustancialmente económica. A las municipalidades les correspondían los ingresos por concepto de los llamados propios de las ciudades y recaudación de ciertos impuestos como el de carnes muertas y carruajes, así también había sido con los cabildos. Pero el nuevo gobierno republicano debía manifestar su soberanía en materia de impuestos y procedimientos financieros, por lo cual pretendió garantizar cierta independencia en la administración de los asuntos municipales definiendo como recursos privativos los ingresos obtenidos por los propios de la villa o ciudad. No obstante, el Ejecutivo ejercía la superintendencia sobre estos. Esta dirección superior sobre los municipios, por un lado, y la definición de una jurisdicción municipal, por otro, determinó una relación tensionada entre ambos niveles de gobierno.

Los presupuestos municipales fueron expresión de esta, pues debían ser aprobados por el gobierno central, al mismo tiempo que correspondían a un acto por el cual la municipalidad ejercía el poder sobre su territorio vinculando sus recursos a planes específicos. Estos adquirieron regularidad a fines de los años 1840 y, a partir de 1851, la aprobación presupuestaria fue constante, así como la ampliación de sus fuentes de ingresos para ejecutarlos, apelando a obtener asignaciones adicionales por parte del Estado ${ }^{17}$. Entre 1853 y 1857 la mayoría de las

\footnotetext{
${ }^{13}$ FMI, Vol. 146, fs. 251-525.

${ }^{14}$ Proyecto de Ley de Régimen Interior elaborado por el Poder Ejecutivo en 1836, FMI, vol.135, Fs. 52-69: Organiza el gobierno interior de la república en intendente, gobernador, subdelegado e inspector de distrito; no menciona a la municipalidad, sino solo para indicar que el gobernador presidirá los ayuntamientos de las capitales cabeceras de departamento. Fue sancionado en 1844.

${ }^{15}$ FMI, vol. 146, años 1835-46, f. 173: Informe de la Intendencia de Coquimbo al Ministro del Interior, 20 de febrero de 1843, denuncia que los departamentos de Illapel, Combarbalá y Ovalle sufrían un estado de atraso lamentable debido a que las municipalidades durante el periodo constitucional correspondiente solo se habían reunido tres a cuatro veces y no con el fin de promover mejoras, sino que para nombrar a las juntas calificadoras y receptoras.

${ }^{16}$ FMI, vol.80. Actas municipales y cartas al Intendente por conflictos políticos y reclamos de traspasar los límites de sus atribuciones por uno u otro lado.

${ }^{17}$ Decretos de aprobación de los presupuestos municipales publicados en Boletín de Leyes y decretos del gobierno (en adelante $B L D$ ), años 1851-1856.
} 
municipalidades en el país obtuvieron este ingreso fiscal ${ }^{18}$. El presupuesto municipal era un mecanismo de fiscalización por parte del poder Ejecutivo que debía autorizarlo, a la vez que de empoderamiento por parte de los gobiernos locales. Estos presupuestos requerían inventariar los ingresos y gastos del municipio, dar cuenta del balance económico y reunir a sus miembros para discutir la siguiente planificación administrativa. Como resultado, abrieron un espacio de negociación a nivel local y entre la municipalidad y el gobierno central y también revelan formas de crecimiento. Desde este otro ángulo, rastrear el proceso de anclaje territorial del Estado a una escala territorial menor como la municipal provoca un cambio de lectura que permite observar otras lógicas no necesariamente equivalentes a las implementadas para organizar el gobierno de las provincias.

\section{La centralización del gobierno local}

Un punto de inflexión ineludible en la trayectoria de la cuestión municipal es la promulgación de la primera Ley de Organización y Atribución de las Municipalidades en 1854 con el fin de desarrollar a nivel local el principio constitucional unitario ${ }^{19}$. A mediano plazo, esta ley consolidó la centralización del gobierno nacional, subordinando a estas corporaciones a la cadena de mando provincial. Esta norma abrió nuevos ámbitos de fiscalización y control a favor del gobierno central. Asimismo, esta vez desde abajo, se buscó ajustar los engranajes de la administración local para proyectar la capacidad de intervención del Ejecutivo hasta la menor escala territorial de poder. De este modo, la cadena de mando pasó a operar en dos ámbitos complementarios: uno, a través del intendente y su influjo sobre la cadena de gobierno interior por medio de los gobernadores, subdelegados e inspectores de distrito (Urzúa, 1970), y dos, a través del reforzamiento del control que ejercían gobernadores e intendentes sobre las corporaciones municipales.

Con todo, los debates legislativos en torno al proyecto de dicha ley y su aprobación exageraron las actitudes reticentes al control central manifestadas por los municipios ${ }^{20}$. Efectivamente, en no pocos aspectos de su funcionamiento rutinario, como la celebración de las sesiones municipales o el registro de los presupuestos, se los alcaldes y regidores se mostraron reacios a dicho control. Sin embargo, no hay que desconocer que hasta mediados de siglo eran espacios informales de autonomía abiertos por la laxitud de las normas previas. Tempranamente en el siglo, el municipio tuvo una considerable independencia política en relación a la posición administrativa subordinada al gobierno central que tendrá hacia fines de la centuria. En estas décadas, también fueron definiéndose sus atribuciones políticas y la referencia constitucional

\footnotetext{
${ }^{18}$ Los oficios y actas contenidas en el volumen 234 del FMI dan cuenta de los arbitrios municipales para procurarse recursos entre los años 1846 y 1854: por concepto de ventas de terrenos, derechos de impuestos por exportación de minerales, derechos de sisa, de carnes muertas, entre otros. Las municipalidades con asignación fiscal, ordenadas de norte a sur, fueron Copiapó, Caldera, Vallenar, Freirina, La Serena, Elqui, Ovalle, Combarbalá, Illapel, San Felipe, Petorca, La Ligua, Putaendo, Los Andes, Valparaíso, Quillota, Casablanca, Santiago, Victoria, Melipilla, Rancagua, San Fernando, Caupolicán, Curicó, Talca, Lontué, Cauquenes, Quirihue, Linares, Parral, Constitución, Chillán, San Carlos, Concepción, Talcahuano, Puchacai, Rere, Coelemu, Lautaro, Nacimiento, Laja, Arauco, Valdivia, Osorno, La Unión, Ancud, Castro, Quinchao, Carelmapu.

${ }^{19}$ Ley sancionada el 8 de noviembre de 1854, BLD año 1854.

${ }^{20}$ Para algunos ejemplos sobre el desorden y la improvisación en el funcionamiento de estas corporaciones, $S C L, 2$ de octubre de 1844, tomo XXXV, p. 403; SCL, 27 de julio de 1854, tomo XXXVI, pp. 89-90; Cámara de Diputados, Sesiones del Congreso Nacional, 14 de junio de 1847, pp. 25-28.
} 
posterior relativa a sus funciones de gobierno interior indica, asimismo, que en la práctica las ejercían.

A partir de 1854, las municipalidades fueron establecidas por ley en la ciudad cabecera de cada departamento del país. La única otra fuente de creación de municipios recayó en el presidente de la República, quien tenía la facultad de establecerlo en otras poblaciones en que así dispusiese. A diferencia de las décadas anteriores, el régimen municipal establecido no contempló la creación de municipios por iniciativa local. El principio de elección popular para conformar los municipios se mantuvo, continuando la tendencia política anterior de legitimación por origen del poder. Sin embargo, el régimen municipal organizó una estructura jerarquizada del gobierno nacional en la cual las municipalidades, como formas de gobierno local, debían ser precedidas por el gobernador o subdelegado respectivo, el cual era designado por el poder Ejecutivo y poseía derecho a veto en las sesiones corporativas. Esta normativo significó un giro decisivo hacia la centralización del gobierno local y una pérdida considerable de autonomía municipal. En este nuevo marco regulatorio, la municipalidad conservó sus funciones electorales de nombrar las juntas calificadoras y las revisoras de las inscripciones y de las elecciones locales y parlamentarias, constituyéndose así en sedes de los procesos electorales. No obstante, el municipio era ahora también un nivel de gobierno más permeable a la intervención del gobierno central. Como resultado, este permaneció como un espacio tensionado por el proceso de centralización estatal que perseguía la consolidación de las instituciones y agentes del gobierno central, como los intendentes y gobernadores, en todas las escalas espaciales del territorio nacional.

La finalidad de la ley orgánica fue también imponer a las municipalidades un orden burocrático inserto en el proceso de formalización administrativa del poder Ejecutivo. Un reflejo de este procedimiento quedó patente en el Anuario Estadístico de la República que en adelante las registró cuantitativamente, visibilizando sus agentes y sus cuentas financieras a partir de 1860 . El registro era una forma de control, pero también la preocupación administrativa por parte del Ejecutivo ante los diferentes casos que representaban cada municipalidad. Los esfuerzos por acercar el conocimiento estatal a la realidad local habían comenzado en 1840, de la mano de la formación de la Oficina de Estadísticas, por medio de la elaboración de encuestas que cada gobernador departamental debía levantar en las municipalidades de dicho territorio. ${ }^{21}$ Ubicadas en las cabeceras departamentales, el municipio era la entidad de gobierno local y, desde las autoridades ejecutivas, gobernar adquiría el significado de entender ese territorio. Así lo resume la Memoria del Ministerio del Interior en 1863: "El Gobierno ha tenido muy presente estas consideraciones y ha tomado siempre en cuenta... los informes i reclamos de cada municipalidad. En asuntos de esta naturaleza, todo es local" 22 .

Desde el ángulo local, las actas de varias municipalidades -entre otras: La Ligua, Los Andes, Valparaíso, Concepción, Freirina, San Antonio de la Unión, ciudad de la Florida, San Bernardo, Curicó, Melipilla, Petorca, Coelemu, Santiago, Copiapó- demuestran la constancia de los procesos eleccionarios, la frecuencia de sus sesiones y los esfuerzos por regularizar el funcionamiento administrativo. Y constatan también que la implementación de un régimen municipal entendido moderno desde la lógica centralista, fue una política criticada como

${ }^{21}$ FMI, vol.122: Encuesta estadística sobre demarcación territorial, montañas, topografía, hidrografía y división agrícola; ingresos municipales; división administrativa; número de pueblos, cárceles, obras públicas, establecimientos hospitalarios, escuelas, y orden público.

${ }^{22}$ FMI, vol. 48. 
retrógrada y desafiante para las libertades individuales. Las corporaciones municipales reivindicaron sus anteriores espacios de autonomía y denunciaron ante el poder Ejecutivo el "...delito de instalar por la fuerza una municipalidad"23. En Vichuquén, el año 1863, el gobernador interino convenido con el intendente de la provincia había instalado una municipalidad de personas "extrañas a aquel Departamento, pisoteando los derechos de la corporación elegida popularmente e instalada en la forma legal por el Gobernador propietario...". Era inconcebible que el supremo gobierno pudiera ignorar que las motivaciones de tal ilegítimo acto respondían a intereses particulares “...cuando ellas se refieren a la constitución del poder municipal en un departamento..." 24 . Las tensiones de naturaleza política fueron subrayadas por quienes una década más tarde promovieron una reforma municipal con el fin autonomizar a dichas corporaciones de la intervención directa por parte del gobierno central. Bastante menos reconocidas fueron las tensiones de naturaleza económica.

En el contexto político del cambio de fisonomía institucional provocado por las reformas constitucionales sancionadas entre los años 1873 y 1876, las cuales limitaron las facultades del poder Ejecutivo, tomaron forma las ideas favorables a la autonomía municipal (Lastarria, 1874). En este marco de subordinación que ya se hacía efectiva, los intentos por disminuir las facultades presidenciales fueron mociones lideradas por los parlamentarios liberales. Era un conflicto doctrinario en el cual, paradójicamente, la configuración de esta agenda a nivel del gobierno local fue realizada por el Partido Conservador. Recién se cristalizó después de la Guerra del Pacífico con la apertura de un ciclo de reformas sancionadas entre 1887 y 1897, como analiza la siguiente sección. La municipalidad se había convertido en el único exponente de organización descentralizada de tipo territorial y, por ende, era un espacio de poder local desde el cual apelar a la autonomía.

El Partido Conservador incorporó esta demanda por autonomía municipal a su programa político presentado públicamente en la Convención de 1878, definida como el ejercicio del gobierno local con entera independencia del gobierno. Esta fue una estrategia en respuesta a las reformas constitucionales promulgadas durante la administración del Presidente Errázuriz (18711876), las cuales ensancharon las bases de poder sobre las cuales se hallaba organizado el gobierno nacional. La cuestión central del debate sobre la reforma constitucional en esta década no fue la descentralización del gobierno local, sino obtener autonomía electoral. Si bien estos objetivos no se contraponen, por el contrario, fueron ideológicamente entrelazados, la reforma significó a mediano plazo una desvirtualización y pérdida de autonomía para estas corporaciones como cuerpos intermedios entre los ciudadanos y el Estado. Hubo una pérdida de espacio político participativo que inmediatamente lamentó Malaquías Concha en su Programa de la Democracia publicado en 1894 como expresión de las aspiraciones del Partido Democrático. “...todo organismo político desde que se constituye, es capaz de gobernarse a sí mismo.” Y, por tanto, era un contrasentido político limitar el poder público por medio de gobernadores e intendentes designados que intervengan en el municipio "embrión del organismo político, la célula primordial, el elemento constitutivo del Estado" 25 . En este debate, conservadores y demócratas coincidieron por diferentes motivos en que el municipio era anterior al Estado.

${ }^{23}$ FMI, vol.48, fojas correspondientes a los años de 1863-64.

${ }^{24}$ FMI, vol.48.

${ }^{25}$ Malaquías Concha, El Programa de la Democracia, pp.51-53. 


\section{El balance de un siglo en la década crucial de 1887-1897}

Los primeros estudios constitucionalistas incorporaron al municipio como un elemento central en la organización territorial del poder político. Ideológicamente, era la expresión genuina de la democracia sostenida en la sociedad civil. Las fuentes examinadas dan cuenta de la vitalidad de ese primer proceso formador de la municipalidad moderna. Sin embargo, la historiografía ha reproducido el diagnóstico de debilidad denunciado por los reformistas de fines de siglo. El argumento doctrinario exageró la parálisis política y económica que aparentemente sufrían los municipios con el fin de convertirlos en espacios de competencia electoral.

Matizada por el criterio político contingente, esta primera mirada predominantemente jurídica hizo un doble diagnóstico de debilidad institucional y económica del municipio que atribuía a la casi secular dependencia administrativa respecto del gobierno central, a la crónica falta de recursos y a la intervención política sobre dicho cuerpo debido a las funciones electorales que ejercía. Si la interpretación republicana de mediados de siglo entendió al municipio como un eslabón territorial del Estado, hacia fines de la centuria la interpretación reformista apuntó a criticar su estatuto institucional para reconvertirla en una entidad autónoma de derecho público. Por consiguiente, tal diagnóstico político inauguró los estudios legales sobre administración pública y las municipalidades, definidas como una persona administrativa de derecho público, es decir, como una entidad con capacidad de actuar, deliberar y mandar, cuya función era la administración de los asuntos locales o gobierno comunal. Desde esta concepción, la reforma constitucional de 1874 había significado restar el poder electoral que poseía el municipio y, en la dimensión gubernativa, estrechó la amarra entre la municipalidad y el eje central del poder Ejecutivo. Podría calificársela, paradójicamente, como una transformación liberal centralizadora del gobierno local.

Asimismo, en este último tercio del siglo XIX, el proceso de integración del Estado nacional habría debilitado al poder local-regional ${ }^{26}$. Para comprenderlo, las leyes de 1887, $1891 \mathrm{y}$ 1897 deben examinarse como un conjunto normativo que provocó resultados contradictorios, porque los objetivos políticos y los administrativos no fueron coincidentes. Los esfuerzos por la autonomía municipal respecto de la tutela del Ejecutivo -en manos de los gobernadores e intendentes- fue un logro de la ley nueva Ley Orgánica de Municipalidades de 1887, pero esta mantuvo la intervención del gobierno central por medio de otras normas que le permitían diferenciar entre municipalidades específicas ${ }^{27}$. Por ejemplo, el presidente de la República tuvo la facultad de alterar el número de miembros que componían un municipio. En esta misma dirección, la llamada Ley de Comuna Autónoma de 1891 mantuvo la vinculación subordinada al gobierno central y estableció nuevas diferencias concretas respecto de las municipalidades de Santiago y Valparaíso, las cuales eran divididas por el presidente de la República determinando circunscripciones que elegían a tres miembros municipales. Finalmente, los efectos de la siguiente ley de 1897 fueron solo electorales, pues restó a las municipalidades sus funciones de institución electoral diferenciándolas de sus funciones administrativas.

Otra fue la experiencia transformadora que esta normativa provocó a nivel gubernativo y de la administración interior, pues este ciclo de reformas implicó perfeccionar la integración subordinada de las municipalidades al engranaje territorial del Estado (Valdebenito, 1973). Las

${ }^{26}$ De acuerdo con el concepto pragmático de poder autónomo definido por Michael Mann como poder infraestructural, p. 20.

${ }^{27}$ Ley Orgánica y de Atribuciones de las Municipalidades de 12 de septiembre de 1887. 
demandas de estas entidades por una mayor independencia recayeron sobre el ámbito ya restringido de resolución de sus asuntos y no cuestionaron la centralización monocéntrica estatal. Los resultados de las reformas municipales de fin de siglo respondieron más bien al ajuste microscópico de los desafíos del gobierno territorial, reforzando en los espacios locales una subordinación que nominalmente se disipaba en los espacios intermedios de las gobernaciones e intendencias. Hasta 1891, el número de municipalidades era muy poco mayor al de los departamentos, porque excepcionalmente (solo en el caso de Chañaral, Viña del Mar y otro) el presidente de la República había usado la facultad establecida por la Constitución de 1833 de crearlas. Esta constatación demuestra que las municipalidades habían sido, hasta entonces, los engranajes territoriales de la división política-administrativa. En cambio, la ley de 1891, que aspiró a descentralizarlas, creó 195 municipalidades nuevas y en el año 1914 ya sumaban 317.

En síntesis, la autonomía municipal respecto de la burocracia estatal no significó otra cosa más que la anulación de los antiguos mediadores para dar paso a una subordinación directa al poder Ejecutivo. De hecho, la ley de 1897 que reformó la Ley Orgánica de Municipalidades reservó para el Estado una serie de herramientas legales que le permitieron controlar de manera eficaz el funcionamiento de las municipalidades, dosificando el acceso a recursos, designando a las autoridades de las corporaciones más relevantes, ejerciendo el derecho a veto en materias sensibles y supervisando la creación de nuevos municipios.

A lo largo de la trayectoria secular descrita se identifican nudos problemáticos que prevalecen, si bien sus sentidos argumentativos fueron distintos. La cuestión de la autonomía municipal no era un problema de gobierno interior, sino uno político en el sentido restringido de competencia partidaria. El análisis histórico-constitucional de estos procesos permiten comprender cómo el gobierno nacional fue estatuido, aplicado y replicado localmente, apoyándose a la vez que diferenciándose en espacios de poder territorial existentes. Las configuraciones territoriales del poder político como problemáticas de gobierno identifican concreciones estatales alternativas, vinculadas a proyectos $\mathrm{y}$ reformas con opciones institucionales específicas que el problema de gobernar a la nación concretó a nivel regional/local.

Por consiguiente, el análisis permite concluir en qué sentido el Estado chileno fue entendido como entidad central de gobierno: no como un carácter consustancial a este, sino paradójicamente, como un proceso construido desde la localidad representada por el municipio. El giro de perspectiva a una mirada desde otro centro de poder, ubicado a nivel local y distinguible del aparato estatal, recupera el protagonismo de las entidades intermedias de gobierno, constatando que hubo procesos denominados nacionalización del poder local a la vez que localización del poder estatal. La cuestión de cómo organizar el gobierno de la naciente república poseyó una dimensión eminentemente nacional que debía concretarse a nivel provincial y municipal. Los esfuerzos y proyectos constitucionales de las primeras dos décadas de vida independiente apoyaron territorialmente la cuestión de la soberanía en algunas instituciones coloniales, las cuales demostraron su fortaleza y flexibilidad para acoger nuevas formas de gobierno. El cabildo fue la lógica representativa inicial y la institución negociadora durante la crisis de la independencia; sin embargo, la república eliminó al cabildo y creó al municipio moderno.

Hubo continuidades en el concepto territorial y funcional de las municipalidades, pero transformaciones radicales en materia de representación política, jurisdicción y responsabilidad administrativa a partir de mediados del siglo XIX. La función electoral del cabildo a principios de la centuria tuvo un rol destacado como bisagra entre la derrumbada estructura imperial y el 
proyecto republicano. A partir de las leyes federales de fines de la década del '20, la elección de los municipales fue una novedad que no fue suficientemente destacada como instauradora de prácticas de gobierno local, sino hasta finales del siglo en el contexto reformista. Al parecer, incluso durante los años de ensayo federalista, el municipio no fue concebido como un poder con injerencia en el gobierno nacional. La instauración del régimen municipal con la primera ley orgánica de municipalidades de 1854 expresó unas opciones políticas específicas y los modos concretos en que esta norma articuló territorialmente el poder político. El municipio experimentó un proceso entrelazado con las autoridades ejecutivas de definición jurisdiccional que definió los alcances de su poder sobre una población y un territorio determinados. Como resultado, el poder Ejecutivo y el local municipal fueron instituciones configuradas y mutuamente transformadas entre estos diferentes niveles espaciales de poder y que no pusieron seriamente en duda la subordinación del segundo al primero.

No obstante, la atención analítica puesta sobre los niveles municipales subraya a estos como lugares que organizaron unos centros poder, permitiendo dinamizar los procesos de institucionalización del poder político como modos concretos de gobierno. Por tanto, constata que la organización del poder municipal ha sido una bisagra clave del proceso de configuración estatal. La Constitución del ' 33 instituyó un Estado unitario que, obviamente, no supone la existencia efectiva del mismo. No podía ser "realmente" unitario, sino que era un proyecto. La estructura estatal establecida era una red político-administrativo que fue creada en espacios provinciales, departamentales y locales, y entrelazada a través de las municipalidades. En consecuencia, suponer sin mayor crítica la intervención estatal sobre los asuntos locales sería anteponer dicho resultado como antecedente, desconociendo el proceso que habría definido el perfil de la relación entre las instituciones de gobierno local y el Estado. En contraste, el fenómeno de la intervención estatal en el ámbito de la municipalidad depende históricamente de la existencia de un Estado con capacidad de acción a nivel nacional. Asimismo, depende de la existencia de aquella institución de gobierno local que llamamos municipalidad. Como contracara, tampoco puede desprenderse como corolario de la premisa anterior, que si el Estado carecía aún de la capacidad de concretar ciertas funciones a nivel territorial del país, las habría dejado en manos de la municipalidad. Esta conclusión sería equívoca si atribuye al Estado funciones que no estuvieron en sus orígenes republicanos y que el reconocible proceso de territorialización local del poder político permite conocer. 


\section{Referencias Bibliográficas}

Adelman, J. (1998). "Spanish-American Leviathan? State Formation in Nineteenth-Century Spanish America. A Review Article". Society for Comparative Study of Society and History: 391-408. doi:10.1017/S0010417598001121.

Alemparte, J. (1940). El cabildo en el Chile colonial: orígenes municipales de las repúblicas hispanoamericanas. Santiago: Universidad de Chile.

Angell, A., Lowden, P. y Thorp, R. (2001). Decentralizing Development. The Political Economy of Institutional Change in Colombia and Chile. New York: Oxford University Press.

Anguita, R. (Comp.). (1912). Leyes promulgadas en Chile. Desde 1810 hasta el $1^{\circ}$ de junio de 1912. Santiago: Imprenta, Litografía y Encuadernación Barcelona.

Annino, A. (1995). "Cádiz y la revolución territorial de los pueblos mexicanos 1812-1821". En A. Annino (Coord.), Historia de las elecciones en Iberoamérica, siglo XIX (pp. 177226). Buenos Aires: Fondo de Cultura Económica. . y Guerra, F.X. (Coords.). (2003). Inventando la nación: Iberoamérica siglo XIX. México D.F.: Fondo de Cultura Económica. . y Ternaviaso, M. (Coords.). (2012). El laboratorio constitucional iberoamericano: 1807/1808-1830. Madrid: Iberoamericana.

Barros Arana, D. (1902). Historia General de Chile: Parte novena: Organización de la República de 1820 a 1833. Santiago: Imprenta Cervantes.

Bello, A. (1885). Obras Completas de don Andrés Bello. Volumen 8: Opúsculos literarios i críticos. Santiago: Impreso por Pedro G. Ramírez.

Bernaschina, M. (1952-1954). Derecho municipal chileno. Santiago: Editorial Jurídica de Chile.

Briseño, R. (1849). Memoria histórico-crítica del Derecho Público chileno desde 1810 hasta nuestros días. Santiago: Imprenta de Julio Belin y Cía.

Boletín de Leyes y decretos del gobierno (BLD), años 1817 a 1898.

Bulpitt, J. (2008). Territory and Power in the United Kingdom. An Interpretation. European Consortium for Political Research Press.

Campos Harriet, F. (1956). Historia constitucional de Chile. Santiago: Editorial Jurídica de Chile.

Carmagnani, M. (2007). “Campos, prácticas y adquisiciones de la historia política”. En G. Palacios (Coord.), Ensayos sobre la nueva historia política de América Latina, siglo XIX (pp. 31-43). México: El Colegio de México.

Carpenter, D. (2001). The forging of bureaucratic autonomy: reputations, networks, and policy innovation in executive agencies, 1862-1928. Princeton: Princeton University Press.

Carrasco, M. (1858). Comentarios sobre la Constitución Política de 1833. Valparaíso: Imprenta y Librería del Mercurio.

Cleaves, P. (1974). Bureaucratic Politics and Administration in Chile. University of California Press. . (1969). Developmental processes in Chilean local government. Institute of International Studies: University of California.

Collier, S. (2012). Ideas y politica de la independencia chilena, 1808-1833. Santiago: Fondo de Cultura Económica. 
. (2003). Chile: The Making of a Republic, 1830-1865. Cambridge: Cambridge University Press.

Concha, M. (1905). El Programa de la Democracia. Santiago: Imprenta de El Siglo XX (segunda edición).

Congreso Nacional de la República (1887). Sesiones de los Cuerpos Legislativos de la República de Chile, 1811 a 1845. Santiago: Imprenta Cervantes.

Constitución Política del Estado de Chile de 1822.

Constitución Política de 1823.

Constitución Politica de la República de Chile de 1828.

Constitución Política de la República de Chile de 1833.

Correa B., A. (1914). Comentarios y concordancias de la Ley de Organización y Atribuciones de las Municipalidades de 22 de diciembre de 1891. Santiago: Librería Tornero.

Donoso, R. (1946). Ideas políticas en Chile. México: Fondo de Cultura Económica.

Drake, P. (2009). Between Tyranny and Anarchy. A Hitory of Democracy in Latin America, 1800-2006. Stanford: Stanford University Press.

Estefane, A. (2017). "Estado y ordenamiento territorial en Chile, 1810-2016". En I. Jaksic y F. Rengifo (Eds.), Historia política de Chile, 1810-2010. Tomo II: Estado y Sociedad (pp. 87-138). Santiago: Fondo de Cultura Económica.

Faúndez, J. (2011). Democratización, desarrollo y legalidad, Chile, 1831-1973. Santiago: Ediciones Universidad Diego Portales.

Fernández, J. (2007). El ibañismo (1937:1952): Un caso de populismo en la política chilena. Santiago: Instituto de Historia, Universidad Católica de Chile.

Foucault, M. (2006). Seguridad, territorio, población. Curso en el College de France (19771978). Buenos Aires: Fondo de Cultura Económica.

Galdames, L. (1925). Historia de Chile. La evolución constitucional, 1810-1925. Santiago: Balcells \& Co.

Gil, F. (1969). El sistema político de Chile. Santiago: Editorial Andrés Bello.

Grindle, M. (2009). Going Local. Decentralization, Democratization, and the Promise of Good Governance. Princeton: Princeton University Press.

Guerra, F.X. (1992). Modernidad e independencias. Ensayos sobre las revoluciones hispánicas. México: Editorial Mapfre, Fondo de Cultura Económica.

Heisse, J. (1974). Historia de Chile: el periodo parlamentario, 1861-1925. Santiago: Editorial Andrés Bello.

(1950) Historia constitucional de Chile. Santiago: Editorial Jurídica.

Illanes, M.A. (2003). Chile Des-centrado. Formación socio-cultural republicana y transición capitalista (1810-1910). Santiago: LOM Ediciones.

Irarrázaval, M.J. (1916). El municipio autónomo: discursos pronunciados sobre tan importante asunto, en las sesiones del Senado de 1889 precedidos de la biografía de este ilustre hombre público. Santiago.

Lastarria, J.V. (1874). Lecciones de Política Positiva. Santiago: Imprenta de El Ferrocarril.

Lemperiere, A. (Ed.). (2014). Tomo 3: Estado. En J. Fernández Sebastián (director), Diccionario político y social del mundo iberoamericano. Conceptos políticos fundamentales, 17701870. Madrid: Universidad del País Vasco, Centro de Estudios Políticos y Constitucionales.

Letelier, V. (1917). La génesis del Estado y sus instituciones fundamentales. Buenos Aires: Cabaut y Cía. Editores. 
(1894). La ciencia del derecho administrativo, lección de apertura del curso de 1894. Santiago: Imprenta Cervantes.

Ley de Régimen Interior, 10 de enero de 1844.

Ley Orgánica y de Atribuciones de las Municipalidades de 12 de septiembre de 1887.

Loughlin, M. (1996). "Understanding Central-Local Government Relations". Public Policy and Administration 11 (2), 48-65.

Loughlin, J., Hendriks, F. y Lidström, A. (2011). The Oxford Handbook of Local and Regional Democracy in Europe. Oxford: Oxford University Press.

Mann, M. (1997). Las fuentes del poder social, Tomo II. Madrid: Alianza Editorial.

Marcel, M. (1994). "Decentralization and Development". En G. Ramis (Ed.), In Route to Modern Growth: Latin America in the 1990s. Washington D.C.: The Inter-American Development Bank.

O’Neill, K. (2005). Decentralizing the State. Elections, Parties, and Local Power in the Andes. New York: Cambridge University Press.

Peña, F.D. (1855). De las municipalidades en Chile i de su organización i atribuciones. Memoria presentada ante la Facultad de Leyes de la Universidad de Chile. Santiago.

Posner, P. (2003). "Local Democracy and Popular Participation: Chile and Brazil in Comparative Perspective". Democratization 10 (3), 39-67.

Reglamento para el arreglo de la autoridad ejecutiva provisoria sancionado el 14 de agosto de 1811.

Reglamento Constitucional Provisorio de 1812.

Reglamento para el gobierno provisorio de 17 de marzo de 1814.

Reglamento Provisorio para el Régimen de las Provincias de 19 de enero de 1827. Santiago: Imprenta de la Biblioteca.

Rehren, A. (2001). "Local Government in Authoritarian Chile". En A. Farazmand (Ed.), Handbook of Comparative and Development Public Administration (pp. 605-615). Nueva York: Marcel Dekker Inc.

Roberts, K. (1998). Deeping Democracy? The Modern Left and Social Movements in Chile and Peru. Stanford: Stanford University Press.

Rojas, B. (2010). El “municipio libre”, una utopía perdida en el pasado: los pueblos de Zacatecas, 1786-1835. México: Instituto Mora.

Roldán, A. (1913). Elementos de Derecho Constitucional de Chile. Santiago: Sociedad Imprenta Litografía Barcelona.

Rosanvallon, P. (2015). El buen gobierno. Buenos Aires: Editorial Manantial.

Rose, N. y Miller, P. (1992). "Political Power beyond the State: Problematics of Government". The British Journal of Sociology 43 (2), 173-205.

Rosenfeld, A., Rodríguez, A. y Espinoza, V. (1989). "La situación de los gobiernos locales en Chile". En J. Borja et al. (Eds), Descentralización y democracia. Gobiernos locales en América Latina (pp.185-239). Santiago: CLACSO.

Salazar, G. (2014). Una perspectiva social sobre las municipalidades en Chile. Santiago: Instituto Chileno de Estudios Municipales. (2006). Construcción de Estado en Chile (1800-1837). Democracia de los “pueblos”, militarismo ciudadano. Golpismo oligárquico. Santiago: Editorial Sudamericana.

Salazar, G. y Pinto, J. (1999). Historia contemporánea de Chile. Tomo I: Estado, legitimidad, ciudadanía. Santiago: LOM Ediciones. 
Sanhueza, M.C. (2008). "La primera división político-administrativa de Chile, 1811-1826". Historia 41 (2), 447-493.

Shapiro, I., Skowronek, S. y Galvin, D. (Eds.). (2006). Rethinking political institutions. The art of the State. New York, Londres: New York University Press.

Scully, T. (1992). Los partidos de centro y la evolución política chilena. Santiago: CIEPLAN.

Serrano, S. (2008). "La representación en el Reino de Chile: 1808-1814". En A. Ávila y P. Pérez Herrero (Comps.). Las experiencias de 1808 en Iberoamérica (pp. 491-508). Alcalá de Henares y México D.F.: Universidad de Alcalá de Henares y Universidad Autónoma de México.

Tocqueville, A. (1835-1840). Democracy in America. Nolla, E. (Ed.). (2012). Indianapolis: Liberty Fund.

Valdebenito, A. (1973). Evolución jurídica del régimen municipal en Chile (1541-1971). Santiago: Editorial Jurídica de Chile.

Valdivia, V., Álvarez, R. y Donoso, K. (2012). La alcaldización de la política. Los municipios en la dictadura pinochetista. Santiago: LOM Ediciones.

Valencia A., L. (Comp.). (1951). Anales de la República. Santiago: Imprenta Universitaria.

Valenzuela, A. (1977). Political Brokers in Chile: Local Government in a Centralized Polity. Durham: Duke University Press.

Valenzuela, S. (1985). Democratización vía reforma: la expansión del sufragio en Chile. Buenos Aires: Ediciones IDES.

Véliz, C. (1980). The Centralist Tradition of Latin America. Princeton: Princeton University Press. 